on adaptations of enzyme pathways to substrate usage, selection of specific enzyme isoforms with acclimation, allosteric modulation and homoeoviscous adaptations of membrane lipids related to the degree of lipid saturation that may alter enzyme properties of membranebound enzymes. Yet, given the plasticity of response of individual ectotherms to seasonal climatic conditions, the evolution modulations was probably conservative. As the authors comment, the overall plasticity of individual ectotherms in adapting to temperature is dependent upon a complex of physiological adjustments; taken together, these adjustments result in dynamic regulatory abilities well beyond those found in experiments with isolated tissues and with individuals examined under controlled conditions.

Another chapter deals with thermal stress effects that induce adaptations in of specific cellular and biochemical

seasonal tolerance limits, freeze tolerance and avoidance, and with the distribution of animals according to multivariate factors such as stress to combined extremes of both salinity and temperature.

The final chapter is concerned with the effects of temperature upon reproduction, development and growth. A just amount of attention is paid to insect development, particularly to seasonal developmental arrest (diapause) which is largely controlled by a kind of integral relating thermal history and the length of the daily photoperiod. The remarks at the end of this chapter emphasize the importance of temperature in the natural selection of regional thermal phenotypes, well adapted to their niches. All of the chapters end with similar summary conclusions that are one of the real values of this short book. $\square$

John L. Roberts is a Professor in the Department of Zoology, University of Massachusetts, Amherst, Massachusetts 01003, USA.

\section{Labelling business}

\section{Arthur J. Birch}

Organic Chemistry, The Name Game: Modern Coined Terms and Their Origins. By Alex Nickon and Ernest F. Silversmith. Pergamon: 1987. Hbk £45, \$75; pbk £18, $\$ 29.50$.

Chemists miss the free flights of fancy, unconstrained by inhibitory realities, which many of their academic colleagues can undertake. With less opportunity, they occasionally play.

John Read once said "A chemist is a poet who has taken the wrong turning". His book Humour and Humanism in Chemistry (1947) is a good illustration of this, with gentle, intelligent and sensitive humour, based on scientific relevance, conveyed through rounded stories and poems in English and German. Another classical example of humour was the Berichte der Durstigen Chemischen Gesellschaft of 1886 , which was so like the authentic one that it is to be found bound with the Berichte in the Cambridge University Library. This journal presented surprising scientific insights, for example benzene ring carbons represented by 'blue-headed' monkeys, with their six tails coiled together in the centre - the aromatic 'sextet' about 40 years before Robinson.

This kind of play favourably contrasts with drawing cats' whiskers on aromatic rings, and some of the present book reminds me of the Disney cartoon with a hippopotamus ballet, danced in tutus. It reads like a scrap-book of very variable quality, despite attempts to organize it into themes. The mode of selection of items is hard to discern and there is little to support Read's suggestion of the chemist as a poet. It has a serious purpose in collecting together many given names, but the trivial and the significant are largely indistinguishable. I met at least half of the names for the first time, and do not expect to encounter them again.

I know that I should review this book, and not one yet to be written, but there is a serious gap in the literature concerning chemical names, which have to be invented and should help people in the formulation and expression of ideas. Names devised systematically for computers are so incomprehensible to human beings that they do not assist such creative mental activities, although they permit easy regurgitation of information. As this book shows, the invention of unsystematic names is sometimes rational, based for example on salient aspects of molecular shape, but the results are often fanciful or personal (perhaps, as with a tattoo like "I love Lucy", some of the authors may wish later that they could change their minds).

The emphasis here is that the process is fun, but names should not be invented solely to amuse the inventors or boost their egos. One great mystery in this field, on a par with Fermat's Last Theorem in mathematics, is the origin of 'barbiturate' - did von Baeyer indeed have a close friend named Barbara? This sort of problem is not rationally soluble, but, like the song the Sirens sang, an answer is not beyond all conjecture.

'Trivial' names are usually just that, and it does not matter what they are except short, euphonious and easy to recall. There are, however, other instances of classification where the implications of words are important. Why did the Ingoldian 'electrophilic' and 'nucleophilic' replace the earlier and more correct 'anionoid' and 'cationoid' of Lapworth and Robinson even though all bond-forming reactions involve electrons? Perhaps people had difficulties in remembering which pole is which; perhaps authoritative persistence prevailed. Another example is 'acetogenin' in biosynthesis, which was pushed to replace the earlier and correct 'polyketide'. The latter word indicates immediately the salient feature of the biosynthetic pathway, while the former is misleading and wrong not only on linguistic and scientific grounds but because it runs counter to the accepted convention of 'genin' when used as a suffix. Why therefore was it invented? Perhaps there should be some neutral refereeing system for rival trivial names.

Another facet not adequately examined here, although the case is mentioned, is illustrated by the superb published letter of Jack Edward (transparently disguised as Aloysius S. Smith) about names for directed bonds in hydroaromatic systems, which appeared at a time when a rash of these had broken out following the advent of the useful 'axial' and 'equatorial'. It is necessary to read this letter in full to appreciate its impact. Not before getting half way through does one smell a rat, which then becomes extravagantly odorous. My first suspicion, I recall, was aroused by a reference to Eni Meni and Mini Mo, J. Hotsitotsi Inst. Japan. The result was not only to amuse, but to ask the question whether similar 'serious' contributions are equally ridiculous; indeed, it killed by ridicule the quite unnecessary proliferation of names. Very many in this book could go the same way without loss, and some have done so.

Let me, however, not be too grudging. The book is clearly a labour of love, and is well printed and legible. Although I cannot imagine reading it sequentially, one can open it anywhere at random, without bothering much about what comes before or after, and so it is ideal for the bedside. More importantly, the contents underly some significant aspects of the sociology of science (including the rather child-like attitudes of some scientists outside their work), and they are uniquely informative. Here are to be found anecdotal and often unpublished accounts not available anywhere else, especially not in scientific papers. I was intrigued to see a discussion on the origin of 'nor', which I have used for steroids for over 40 years without finding out its origin.

The world of chemical research is a small one and many of its inhabitants will find in this book interesting sidelights on friends and colleagues. Libraries should have it, and organic chemists will, I think, find it interesting to browse in at leisure. I only wish .

Arthur J. Birch is Emeritus Professor in the Department of Organic Chemistry, Australian National University, GPO Box 4, Canberra, ACT 2601, Australia. 